DISTRIBUTION STATEMENT A. Approved for public release; distribution is unlimited.

\title{
Effects of Disturbance on Populations of Marine Mammals
}

\author{
Erica Fleishman, Ph.D. \\ John Muir Institute of the Environment \\ The Barn \\ One Shields Ave. \\ University of California \\ Davis, CA 95616 \\ phone: (530) 754-9167 fax: (530) 754-9141 email: efleishman@ucdavis.edu
}

Award Number: N00014-12-1-0274

\section{LONG-TERM GOALS}

Our long-term goal is to develop transferable models of the population-level effects of anthropogenic and natural disturbances on marine mammals. Disturbances can affect the physiology or behavior of animals, which in turn may lead to changes in demographic rates and viability. Population-level effects of disturbance also may cascade among species. However, it has proven difficult to identify and model the mechanisms by which individual-level responses to disturbance might propagate to the population level. A clear, quantitative understanding of such mechanisms will inform assessment of trade-offs among potential responses of species to environmental changes and diverse human activities.

\section{OBJECTIVES}

Translate conceptual models of effects of disturbance on behavior or physiology, health, vital rates, and population dynamics into quantitative models for different taxa.

Prioritize data collection for estimation of population-level effects of different types of disturbance on marine mammals with different life-history attributes.

Examine the extent to which collection of high-priority data currently is feasible in terms of time, money, and technology.

Examine inferences about effects of disturbance on individuals and populations that can be drawn on the basis of limited empirical information or with expert elicitation.

Compare inferences about population-level effects of disturbance that are based on extensive empirical data to those based on expert elicitation.

\section{APPROACH}

Most of the work is conducted by a multidisciplinary group of approximately 15 individuals, many of whom participated in an earlier phase of the work. The group holds about two face-to-face workshops of three days each per year. Meetings are held in locations that minimize travel time and expenses for 


\section{Report Documentation Page}

Form Approved

OMB No. 0704-0188

Public reporting burden for the collection of information is estimated to average 1 hour per response, including the time for reviewing instructions, searching existing data sources, gathering and maintaining the data needed, and completing and reviewing the collection of information. Send comments regarding this burden estimate or any other aspect of this collection of information,

including suggestions for reducing this burden, to Washington Headquarters Services, Directorate for Information Operations and Reports, 1215 Jefferson Davis Highway, Suite 1204, Arlington

VA 22202-4302. Respondents should be aware that notwithstanding any other provision of law, no person shall be subject to a penalty for failing to comply with a collection of information if it

does not display a currently valid OMB control number.

1. REPORT DATE

30 SEP 2014

4. TITLE AND SUBTITLE

Effects of Disturbance on Populations of Marine Mammals

6. $\operatorname{AUTHOR}(\mathrm{S})$

7. PERFORMING ORGANIZATION NAME(S) AND ADDRESS(ES)

University of California,John Muir Institute of the Environment,One Shields Ave.,Davis,CA,95616

9. SPONSORING/MONITORING AGENCY NAME(S) AND ADDRESS(ES)

3. DATES COVERED

00-00-2014 to 00-00-2014

5a. CONTRACT NUMBER

5b. GRANT NUMBER

5c. PROGRAM ELEMENT NUMBER

5d. PROJECT NUMBER

5e. TASK NUMBER

5f. WORK UNIT NUMBER

8. PERFORMING ORGANIZATION

REPORT NUMBER

10. SPONSOR/MONITOR'S ACRONYM(S)

11. SPONSOR/MONITOR'S REPORT

$\operatorname{NUMBER}(S)$

12. DISTRIBUTION/AVAILABILITY STATEMENT

Approved for public release; distribution unlimited

13. SUPPLEMENTARY NOTES

14. ABSTRACT

15. SUBJECT TERMS

16. SECURITY CLASSIFICATION OF:

a. REPORT

unclassified b. ABSTRACT

unclassified c. THIS PAGE

unclassified
17. LIMITATION OF ABSTRACT

Same as

Report (SAR)
18. NUMBER 19a. NAME OF

OF PAGES RESPONSIBLE PERSON

5 
the greatest proportion of participants and maximize opportunities to interact with other parties interested in the work and its application. Project oversight is provided by a five-member steering committee [Dan Costa (University of California, Santa Cruz), Erica Fleishman, John Harwood (University of St. Andrews), Scott Kraus (New England Aquarium), and Mike Weise (Office of Naval Research)].

\section{WORK COMPLETED}

The working group met from 16-18 October 2013 at the New England Aquarium in Boston, Massachusetts and from 14-16 May 2014 in Crystal City, Virginia. We held taxon-specific workshops at the annual meeting of the North Atlantic Right Whale Consortium (5-7 November 2013) and in Durham, North Carolina (16-18 June 2014). At their home institutions, subsets of the working group are modeling the population-level effects of disturbances on five marine-mammal taxa: southern elephant seals (Mirounga leonina), northern elephant seals (Mirounga angustirostris), coastal populations of bottlenose dolphins (Tursiops spp.), North Atlantic right whales (Eubalaena glacialis), and Blainville's beaked whales (Mesoplodon densirostris).

Estimation of lipid mass for northern elephant seals. We compared estimates of fat generated with truncated cones versus labeled water while quantifying uncertainty in both methods for northern elephant seals. Incorporation of uncertainty is necessary before using fat or percentage of fat as the measure of health linking behavioral and physiological changes and vital rates.

Assessment of uncertainty in physiological studies of northern elephant seals. We defined the functional relation between maternal health and pup survival, and between health and reproductive rate, in northern elephant seals. First, modeled the relation between foraging success of mothers and pup production (reproductive rate). Second, we we used mark-recapture models to quantify the probability of survival of those pups as a function of wean mass.

State-space modeling of bottlenose dolphin behavior. We fit a simulation model of bottlenose dolphin behavior to data from Doubtful Sound, New Zealand. The simulation model initially was built to inform management of interactions between bottlenose dolphins and boats in the Moray Firth. In this case, the model was applied to data from Doubtful Sound that were collected during scan-samples of focal groups of dolphins from 2000 through 2002. Every $15 \mathrm{~min}$, observers assigned the behavior of the group to one of four categories (travelling, foraging, resting, socializing). The respiration rate of a focal individual was recorded during each scan sample.

Population-level effects of mid-frequency active sonar on Blainville's beaked whales. We developed and published the first empirical risk function that combined passive acoustic detection data and empirical Navy sonar data to estimate the probability that Blainville's beaked whale will be disturbed by mid-frequency active sonar exercises over an full year.

Expert elicitation on movements of North Atlantic right whales. We previously used a state-space model to estimate movement, health, and survival of North Atlantic right whales. That analysis incorporated information on both the prior distribution of values of a parameter and the likelihood that a given value of a parameter is accurate. The informed priors were based on one person's professional judgment, and as a result the effects of uncertainty in the priors on estimates of movement were unknown. Estimates of movement, especially into and out of the mid-Atlantic, depended strongly on the priors. Accordingly, we used expert elicitation with the aim of better informing the priors and 
highlighting gaps in knowledge. We focused on the proportion of females and males in the population that were present during each of the four seasons, as represented by one month. We also estimated the proportion of females and males that move into, or remain within, the mid-Atlantic during January.

Relations between stress and population-level effects of disturbance. We organized a discussion among members of ONR's stress and population-level effects groups. To date, our working group's models primarily have focused on measures of health that are based on energy rather than physiology and that may affect vital rates. We do not expect all stress metrics to be associated with heath or vital rates. There is value in simply examining correlations, and many reasons why correlations may be weak. However, if correlations are strong, then it may be worthwhile to pursue analyses that are more rigorous. Participants suggested that it may be feasible to develop a composite measure of health on the basis of multiple variables. Such a metric could become an input to models of population-level effects and could be used to assess relative health of multiple populations. We hope to continue communication between the groups.

Population-level effects of sound on North Atlantic right whales. The participants in the Durham workshop developed a conceptual model of potential mechanisms by which right whales might respond to sound. We also developed a corresponding table to document, for each class of response or mechanism, existing data that might inform models, strength of evidence, major uncertainties, options for testing hypothesized relations, and feasibility and priority for testing.

Effects of disturbance on bottlenose dolphins in Sarasota Bay. This work is ongoing. We are running mark-recapture models that estimate survival and reproduction as a function of health (body mass index and white blood cell count) and a separate model of direct relations between demographic rates and prey availability, contaminant load, sea surface temperature, and intensity of recreational and commercial fishing. Quarterly mark-resight data are available for 336 individuals from May 1992 April 2010. Data are classified on the basis of whether animals were seen during standard or nonstandard surveys, which improves estimates of detection probability. Data also extend beyond the standard survey area, improving estimates of movement probabilities. Such improvements increase the precision of survival and reproduction estimates.

\section{RESULTS}

Estimation of lipid mass for northern elephant seals. The uncertainty associated with proportion of lipid in blubber was higher when the labeled water method was applied than when the truncated cones method was applied. Estimates of proportion of lipid that were based on the elliptical truncated cones method and the labeled water method were comparable. Posterior uncertainty in the function between proportion of lipid from elliptical cones and tritiated water was high but included the 1:1 relation within the range of the data points.

Assessment of uncertainty in physiological studies of northern elephant seals. There may be a correlation between the percentage of lipid mass and the probability of survival in northern elephant seals. Measurement error in adult female lipid mass and pup wean mass did not affect the estimated function between maternal lipid mass and pup wean mass. The function between pup wean mass and pup survival also was unaffected. There was a small change in reproductive rate as a function of maternal lipid mass. Process error is unavoidable in many cases in which the ultimate goal is to understand the probability of decline. In most cases, ignoring uncertainty will lead to relatively estimates of probability of decline that are relatively low. 
State-space modeling of bottlenose dolphin behavior. The model-generated predicted activity budgets for animals in Doubtful Sound were not biologically realistic. Data from group follows likely are insufficient to reliably infer motivational states and health of individuals. Successful parameterization required information on the spatial distribution of behaviors and the health of individuals (i.e., respiration rate). Telemetry data may be more useful for this purpose because they can provide information on behavioral state, movement, responses to sound or other disturbances, and potentially on direct measures of health.

Population-level effects of mid-frequency active sonar on Blainville's beaked whales. We estimate the probability that an individual whale might change its behavior (stop foraging) as a function of the received level of sonar. The function predicted a 0.5 probability of disturbance at a received level of $150 \mathrm{dBrms}$ re $\mathrm{mPa}$ (confidence interval: 144 to 155 ) This is $15 \mathrm{~dB}$ lower than the level used historically by the US Navy in their risk assessments but $10 \mathrm{~dB}$ higher than the current $140 \mathrm{~dB}$ step-function (i.e., assumption that a response is certain above $140 \mathrm{~dB}$ ).

Expert elicitation on movements of North Atlantic right whales. After inviting the participants in the elicitation and receiving their informed consent, we circulated the draft questions to the participants. We held a call to discuss the questions and refine definitions of concepts and terms in the questions. The call resulted in a number of revisions to the questions. We then asked the participants to submit responses to the questions by email. For each of 14 questions, we asked for a lower bound, higher bound, estimate of the mode, and confidence that the range of values represented truth. In November, 2013, we participants convened to discuss the compiled, confidential responses. Participants then had the option of changing their answers, and most participants changed at least a few. The elicitation suggested the abundance of right whales in the mid-Atlantic during summer may be greater than what conventional wisdom has recognized. We are in the process of incorporating information from the expert elicitation into the models.

Population-level effects of sound on North Atlantic right whales. The group identified three priorities. First, support remaining processing and cleaning of data from Cape Cod Bay. This might allow tests of a number of hypothesized relations between sound and commensal food-finding and mate finding. Second, consider an expert elicitation on whether masking of sound is related to the probability of ship strike. Third, parameterize models or submodels addressing chronic stress. There are multiple ways to address the third priority, including continued analysis of empirical data; conducting comparative studies in different habitats of North Atlantic right whales, on different right whale populations, or on different types of samples (e.g., blubber, feces, blow); conducting an expert elicitation that would focus on whether stress affects the response, or magnitude or duration of response, to sound sources; and conducting an assessment of evidence and uncertainty that is loosely analogous to the process followed for regional, national, and international climate-change assessments. An elicitation would aim to parameterize a chronic stress or stress-population effects model, whereas the latter assessment would better characterize what is known and the associated level of confidence.

\section{APPLICATIONS}

Multiple public and private sectors wish to understand whether observed changes in animals' behavior or physiology affect probabilities of persistence. Subsistence hunters also wish to understand whether short-term changes in behavior may affect long-term spatial distributions of animals. The concept that behavioral responses to disturbance are not necessarily surrogate measures of population-level responses is widely understood. However, without tractable methods for quantifying population-level 
effects, most sectors will be restricted to estimating exposure of individual animals to disturbances or changes in habitat quantity or quality. Thus, improved understanding of transfer functions might help to guide research and management, and to project how marine mammals will respond to alternative scenarios of human activities, from those that produce sound to climate change to changes in human density and distributions.

\section{RELATED PROJECTS}

The following projects support models of effects of disturbance on individual species: N000141110433 and N000141210213 to Diane Claridge, N000141310134 to Dan Costa, N000141210389 to Scott Kraus, N0001413WX20616 / N0001412WX20919 to David Moretti, and N000141210286 to Len Thomas.

Fleishman is leading a project on cumulative effects of underwater anthropogenic sound on marine mammals for BP Exploration. The project has developed both quantitative and qualitative methods for assessing the aggregated sounds of multiple sources received by a given species during a defined time period in a defined location. The ONR-sponsored project is highly complementary because it quantifies mechanisms by which responses to sound or other disturbances may affect survival, reproduction, and population viability.

\section{PUBLICATIONS}

Moretti, D., L. Thomas, T. Marques, J. Harwood, A. Dilley, B. Neales, J. Shaffer, E. McCarthy, L. New, S. Jarvis, and R. Morrissey. 2014. A risk function for behavioral disruption of Blainville's beaked whales (Mesoplodon densirostris) from mid-frequency active sonar. PLoS ONE 9(1):e85064. [published, refereed]

Pirotta, E., L. New, J. Harwood, and D. Lusseau. 2014. Activities, motivations and disturbance: an agent-based model of bottlenose dolphin behavioral dynamics and interactions with tourism in Doubtful Sound, New Zealand. Ecological Modelling 282:44-58. [published, refereed]

Harwood, J., S. King, R. Schick, C. Donovan, and C. Booth. 2014. A protocol for implementing the interim population consequences of disturbance $(\mathrm{PCoD})$ approach: quantifying and assessing the effects of UK offshore renewable energy developments on marine mammal populations. Scottish Marine and Freshwater Science 5(2). [published] 